\title{
Modelling the settling of suspended sediments for concentrations close to the gelling concentration
}

\author{
Benoît Camenen ${ }^{\mathrm{a}}$, Damien Pham van Bang ${ }^{\mathrm{b}}$ \\ ${ }^{a}$ Cemagref, HHLY, 3 bis quai Chauveau CP 220, 69336 Lyon cedex 09, France \\ ${ }^{b}$ Saint Venant Laboratory, 6 quai Watier BP 49, 78401 Chatou, France
}

\begin{abstract}
This paper deals with the sedimentation of highly concentrated sediment suspensions (cohesive as well as non-cohesive) and the beginning of the consolidation of cohesive sediments. Based on a comparison of existing empirical formulas and experimental data, the particle Reynolds number was shown to be of importance for the behaviour of particularly non-cohesive sediments. In addition it plays a role in determining whether one or two interfaces develop during the sedimentation phase. In the case of cohesive sediments, the estimation of the gelling concentration, although difficult, seems to be fundamental. Some suggestions on the estimation of the permeability coefficient and total settling function are then given in order to improve the modelling of the sedimentation and consolidation behaviour for concentrations close to the gelling concentration.
\end{abstract}

Key words: sedimentation, consolidation, settling velocity, permeability, high concentration, cohesive sediments, gelling concentration

\section{Introduction}

The interest in understanding physical characteristics of cohesive sediment has increased significantly during the last 30 years. Cohesive sediments play an important role in river and estuary engineering because of their capability to bind pollutants. Another important issue is the transport, sedimentation and consolidation of fine sediments in reservoir, navigation channels or harbour basins.

Most of the research has been carried out on the settling of low-concentration mud suspensions (Van Leussen, 1988; Dyer \& Manning, 1999, among others) or on the consolidation regime (Gibson et al., 1967; Been \& Sills, 1981 among others). Few authors (Winterwerp, 1999, Camenen, 2008) have studied hindered settling of cohesive sediments where large concentrations of sediments do affect the settling velocity. Dankers \& Winterwerp (2007) attempted to link the hindered regime with the consolidation regime intro- 
ducing a total settling velocity or settling function including permeability effects. It seems however that many unknowns still exist about the behaviour of a mud suspension at the onset of its gelling concentration (defined as the concentration for which the flocs form a space-filling network, Winterwerp \& Van Kesteren, 2004). In estuaries, wave induced turbulence can strongly affect the hindered regime (Gratiot et al, 2005), which can create highly concentrated fluid mud layer with concentrations close to the gelling concentration. On the other hand, the mechanics of lutocline (interface where a sharp gradient in sediment concentration exists and generally maintained thanks to turbulence) and fluid mud are also strongly affected by the hindered settling velocity of the sediments (Wolanski et $a l, 1989)$. Mehta (1991) also showed that erosion processes are deeply influenced by the state of the mud (fluid, non-consolidated, and consolidated). It is thus fundamental to better understand the behaviour of cohesive sediments close to the gelling concentration.

A study on the effects of the choice of hindered settling formulas for the sedimentation regime is presented in this paper using the Kynch theory (1952). Based on experiments of sedimentation in a quiescent fluid (where turbulence is negligible), the ability of the formulas to induce one or two interfaces depending on the particle Reynolds number is emphasized. The second part of this paper establishes a permeability equation and a total settling function that can be used in an advection-diffusion model.

\section{1DV equations for a sedimentation-consolidation model}

\subsection{Equation for sedimentation and consolidation}

Assuming that solid particles are of the same size, shape and density (a1), that both the solid particles and the fluid of the suspension are incompressible (a2), that the flow is one-dimensional (a3), and that the settling velocity of particles in a dispersion and the dissipation coefficient can be determined by the local particle concentration only (a4), a general 1D equation for the sedimentation and consolidation regimes may be (Toorman, 1996, 1999) :

$$
\frac{\partial c}{\partial t}+\frac{\partial}{\partial z}\left[W_{s k}(c) c\right]+\frac{\partial}{\partial z}\left[D(c) \frac{\partial c}{\partial z}\right]=0
$$

where $W_{s k}(c)$ is the total settling velocity function including permeability effects and $D(c)$ is the total dissipation coefficient, and $c$ the volumetric concentration of matter. The total dissipation coefficient is the sum of the molecular diffusion effects $\left(D_{m}\right)$, consolidation diffusion effects $\left(D_{c}\right)$, and eddy diffusivity or turbulence effects $\left(D_{t}\right)$. The molecular diffusion $D_{m}$ is generally negligible and the eddy diffusivity $D_{t}$ may be estimated using a $k-\epsilon$ turbulence model. However, for an experiment with no hydrodynamic constraints (waves or current) and considering the flow is one-dimensional, the turbulence effects are 
negligible. A sedimentation consolidation experiment is thus represented by three main regimes (Toorman \& Berlamont, 1991; Dankers \& Winterwerp, 2007; cf. Fig. 1) :

1. hindered regime, where the settling velocity is mainly driven by the concentration of particles ( the total pressure minus the neutral pressure of water in pores or effective stress $\left.\sigma^{\prime}=0\right)$;

2. permeability regime, where the settling velocity function is mainly driven by the permeability. This mode physically represents compression and expulsion of pore water $\left(\sigma^{\prime} \approx 0\right)$;

3. effective stress regime, where particle deformation causes further compression $\left(\sigma^{\prime}>\right.$ 0 ; diffusion term due to $D_{c}, c f$. Eq. 1).

The first regime corresponds to the sedimentation regime, whereas the two last regimes correspond to the consolidation regime. However, the permeability regime may be modelled in a similar way as the sedimentation regime, i.e. with $D=0$.

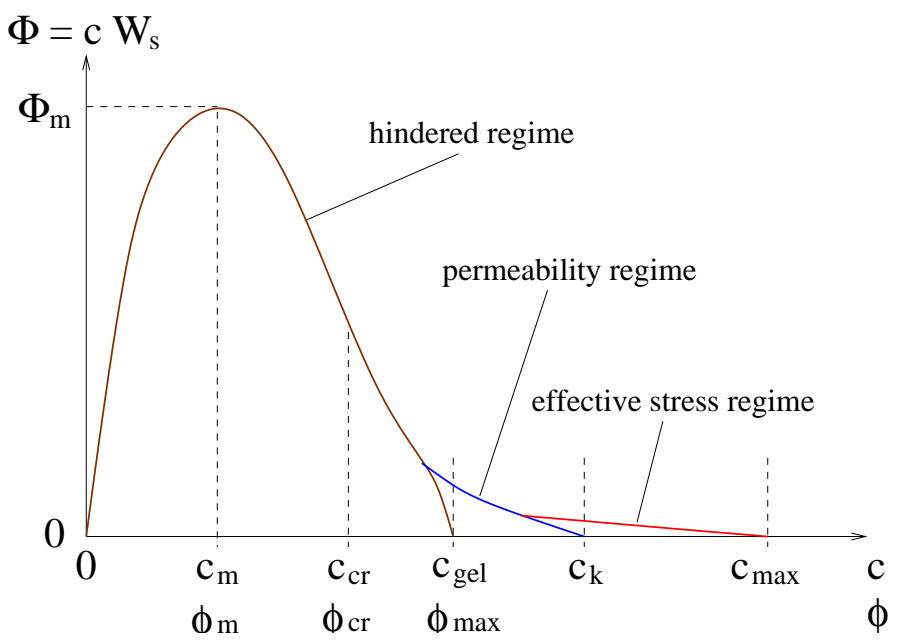

Figure 1: Schematic view of the three different prevailing processes in a sedimentation consolidation experiment from the flux curve $\left(\Phi=c W_{s k}\right)$ as a function of concentration $c$.

The following study will focus on the estimation of the total settling velocity function.

\subsection{The Kynch model for the sedimentation of particles}

Kynch (1952) developed a theory on sedimentation based on the batch experiment. This experiment consists of an initially well-mixed suspension of particles with a concentration uniformly initialized to $c_{0}$ in a settling column subject to gravity only. This suspension will separate into three different phases (one approaching the maximum packing 
particle concentration $c=c_{\max }$ at the bottom of the container, one with a well-mixed suspension $c=c_{0}$ in the middle of the container at the initial average concentration, and clear water at the top of the container). Using the same assumptions as for Eq. 1 and adding that solid particles are all small with respect to the settling column, the mass-balance of the suspended sediments (Eq. 1) simplifies into the simple wave equation in $z$-direction, known as the Kynch equation:

$$
\frac{\partial c}{\partial t}+\frac{\partial \Phi}{\partial z}=0
$$

where $\Phi=W_{s h} c$ is the sediment flux or the Kynch batch flux density function, and $W_{s h}$, the hindered settling velocity, which is assumed to be a function of $c$ and $W_{s 0}$ (settling velocity of a single particle) only.

\section{Sedimentation and batch theory}

The Kynch sedimentation experiment is a simple and interesting test to quantify and calibrate the hindered settling velocity formulas, including the beginning of the permeability regime for cohesive sediments. As larger uncertainties are observed for cohesive sediments because of their stochastic characteristics (density, size and shape of the population of sediments), the hindered settling velocity formulas were first tested against non-cohesive data. The hindered settling formulas studied in this paper were previously presented and compared by Camenen (2008). Equations are reported in appendix A.

\subsection{Non-cohesive sediments}

In case of non-cohesive sediments, the Kynch equation (Eq. 2) is fully valid. Assuming $W_{s h}$ is a function of concentration only, Kynch (1952) showed that Eq. 2 may be rewritten as follows:

$$
\frac{\partial c}{\partial t}+W_{s 0} F(c) \frac{\partial c}{\partial z}=0
$$

where $f(c)=W_{s h} / W_{s 0}$ corresponds to any semi-empirical equation for the hindered effects on the settling velocity, and

$$
F(c)=\frac{\partial[c f(c)]}{\partial c}
$$

Eq. 3 may be solved by integrating along the characteristic lines $d z / d t=W_{s 0} F(c)$ (method of characteristics). Concentration gradients increase when the characteristic lines converge (Winterwerp \& Van Kesteren, 2004). Moreover, $F$, and therefore $\partial \Phi / \partial c$, may have a minimum at $c=c_{c r}$. For $c<c_{c r}, d F / d c<0$, and two interfaces (upper interface 
(a)

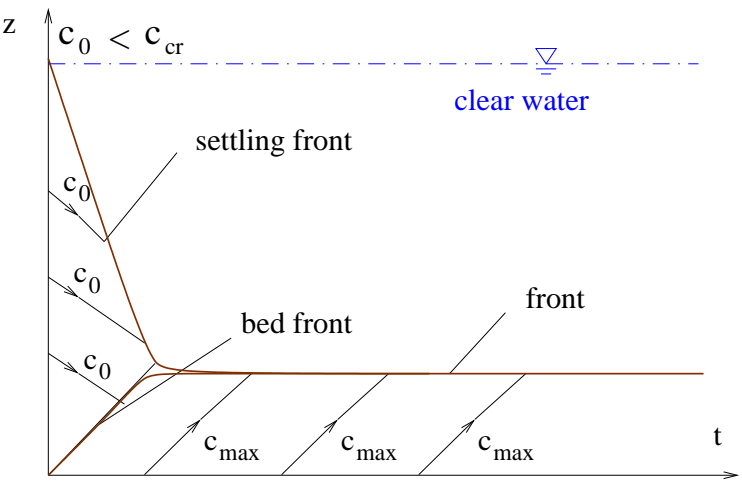

(b)

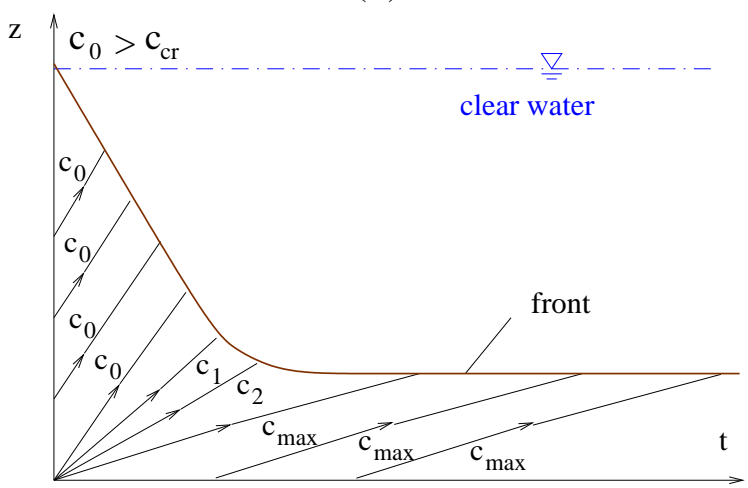

Figure 2: Schematic view of the development of two (a) or one (b) interfaces in the Kynch sedimentation test with non-cohesive sediments depending on the initial concentration $c_{0}$ (the lines with an arrow correspond to the iso-concentration lines with $c_{0}<c_{1}<c_{2}<c_{\max }$ ).

corresponding to the settling front and lower interface corresponding to the bed front) will develop ( $c f$. Fig. 2a). For $c>c_{c r}, d F / d c>0$, and only the upper interface develops ( $c f$. Fig. 2b).

The choice of the hindered settling formulas may significantly influence the results for the Kynch theory, even if the formulas yield similar prediction for the settling velocity. Indeed, if two hindered functions $f_{a}$ and $f_{b}$ yield same result for $c=c_{1}\left(f_{a}\left(c_{1}\right) \approx f_{b}\left(c_{1}\right)\right)$, $F_{a}\left(c_{1}\right)=\left\{\partial\left[c f_{a}(c)\right] / \partial c\right\}_{c=c_{1}}$ may differ significantly from $F_{b}\left(c_{1}\right)=\left\{\partial\left[c f_{b}(c)\right] / \partial c\right\}_{c=c_{1}}$. It results from the variability of the semi-empirical expressions for the hindered functions (see appendix A). Thus, the prediction of $c_{c r}$, which separate the two regimes or of $c_{m}$ for which the maximum flux density $\Phi=c W_{s}$ is reached may vary significantly with the choice of the hindered settling formula as $c_{c r}$ and $c_{m}$ correspond to the 1st and 2nd derivatives of the function $F$ with respect to $c$, respectively.

The particle Reynolds number $R_{e *}=W_{s} d / v$ ( $v$ is the kinematic viscosity of water), which characterizes the flow regime around a settling particle, is a measure of the relative weight of the inertial forces and frictional forces to the total drag forces. For a single particle, the drag coefficient decreases with the particle Reynolds number. And for large particle Reynolds numbers, the velocity of a particle may thus be less affected by the wake of the surrounding particles. Based on experimental results, Richardson \& Zaki (1954) suggested the formula $f=(1-c)^{n}$ where the index $n$ decreases with the particle Reynolds number from $4.8\left(R_{e^{*}} \ll 1\right)$ to $2.2\left(R_{e^{*}} \gg 1\right)$. With this formula, the maximum of the function $c f$ increases from 0.06 to 0.14 for large $R_{e *}$; and, as a consequence, knowing that $d\left(c_{m} f\left(c_{m}\right)\right) / d c=0$ and $f\left(c_{\max }\right)=0$, the curve steepens when $c>c_{m}$, and the coordinate of the inflection point $\left(c=c_{c r}\right)$ also increases with the particle Reynolds number (see also in Fig. 4). Using Rowe's (1987) empirical fit for $n$, solutions may be obtained with the 
Richardson \& Zaki equation as functions of the particle Reynolds number $R_{e^{*}}$ :

$$
\begin{aligned}
& c_{m}=\frac{1}{n+1}=\frac{1+0.175 R_{e *}{ }^{3 / 4}}{5.7+0.586 R_{e *}^{3 / 4}} \\
& c_{c r}=\frac{2}{n+1}=\frac{2+0.35 R_{e *}^{3 / 4}}{5.7+0.586 R_{e *}^{3 / 4}}
\end{aligned}
$$

$c_{m}$ and $c_{c r}$ are increasing functions of $R_{e *}\left(0.18<c_{m}<0.30\right.$ and $\left.0.36<c_{c r}<0.60\right)$.

Using a large data set from batch experiments (Oliver, 1961; Shannon et al., 1964; Baldock et al., 2004), the flux density function $\left(c f=\Phi / W_{s 0}\right)$ is plotted in Fig. 3 versus the relative concentration $c / c_{\max }$ with the particle Reynolds number emphasized. The general behaviour of the Richardson \& Zaki formula is confirmed by the data. A hindered settling formula should thus take into account the effect of the particle Reynolds number. Due to the scatter in the data and relatively small number of data points, it is however difficult to precisely identify the position of the critical concentration $c_{c r}$ (inflection point). Only an analytical expression of $f$ (or a curve fitting of the data) can be used to estimate $c_{c r}$.

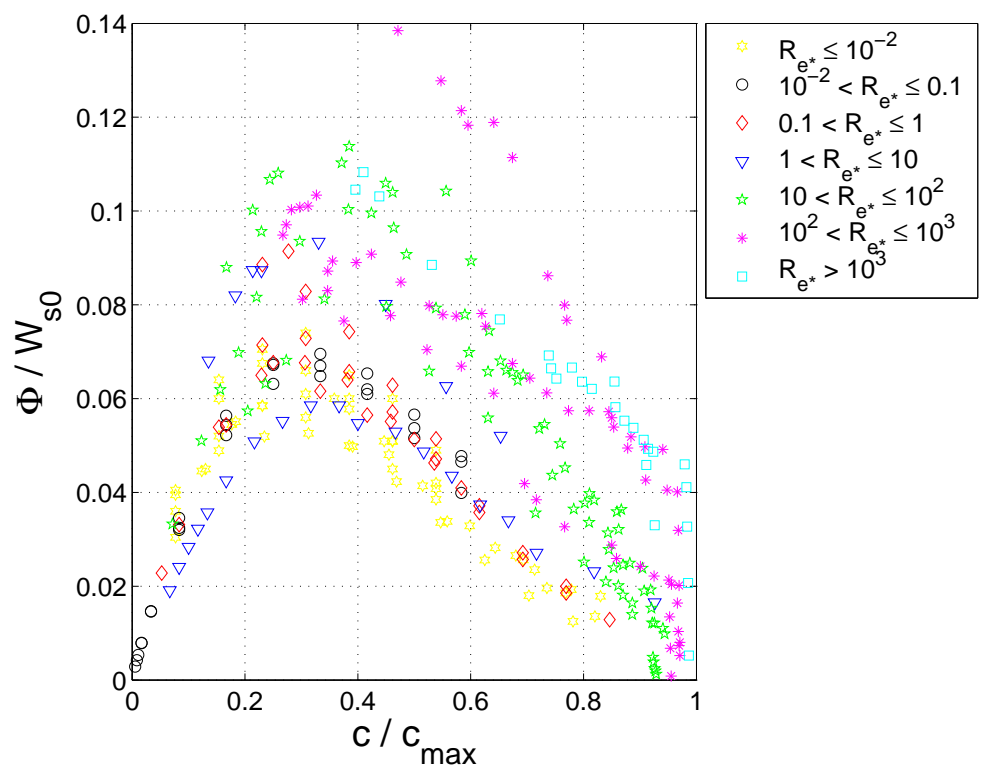

Figure 3: Flux density function $\left(\Phi / W_{s 0}=c f\right)$ as a function of the relative concentration $c / c_{\max }$ for a range of particle Reynolds numbers $R_{e *}$.

Expressions for $c f$ and $F$ are reported in the literature ( $c f$. Camenen, 2008 for details). The Richardson \& Zaki (1954), Souslby (1997, p.135-136), Winterwerp (1999) and Dankers \& Winterwerp (2007) formulas, as well as the modified Richardson \& Zaki 
formula and Camenen formula based on mixture theory (Camenen, 2008) are plotted as a function of concentration in Fig. 4 (see Appendix for the description of the formulas). Following Camenen (2008), the modified Richardson \& Zaki formula will be used as a reference :

$$
\frac{W_{s}}{W_{s 0}}=(1-c)^{n-1}\left(1-\frac{c}{c_{\max }}\right)^{c_{\max }}
$$

(a)

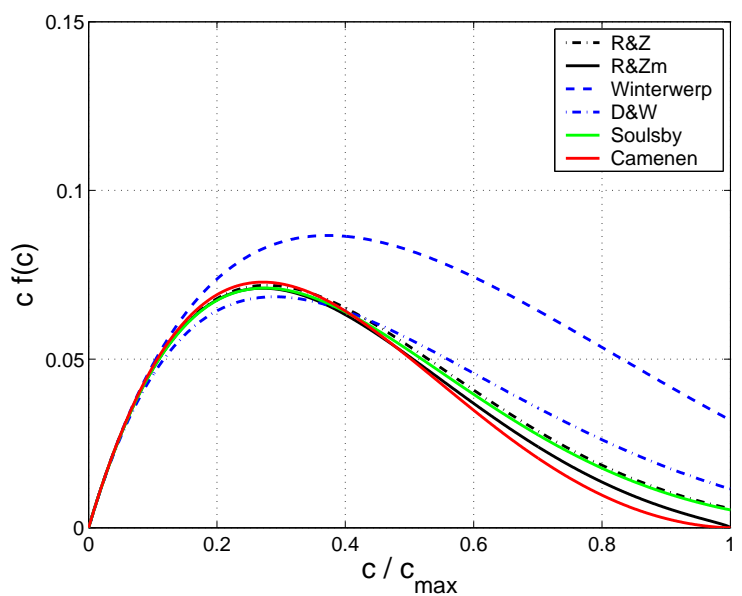

(c)

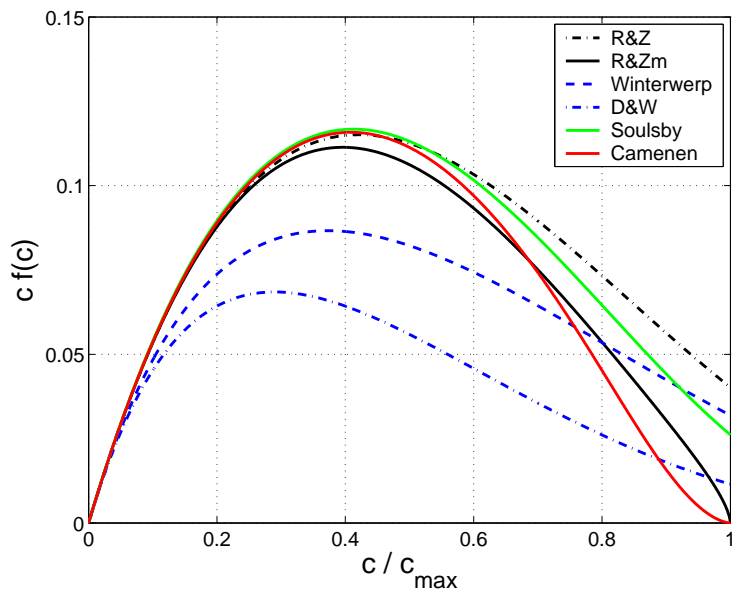

(b)

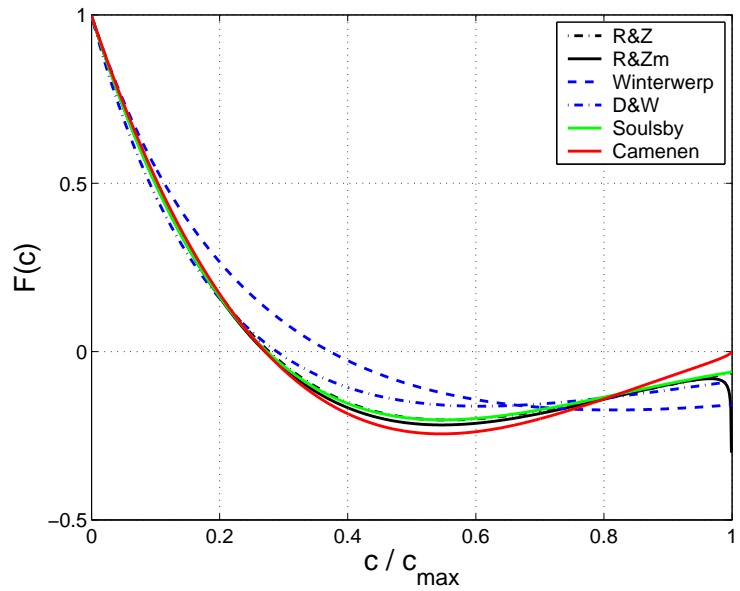

(d)

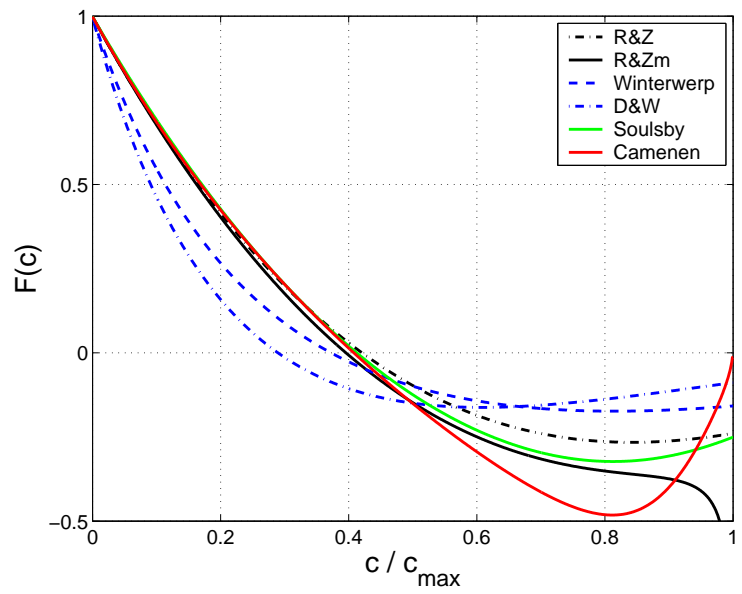

Figure 4: Variation of the flux density functions $\Phi=c f$ (a and $\mathrm{c}$ ) and $F$ (b and d) with the relative concentration $c / c_{\max }$ using the different studied formulas for two different particle Reynolds numbers $R_{e^{*}}=0.1$ (a and b) and $R_{e *}=100$ (c and d).

The flux density function $c f$ using several formulas is plotted against the volumetric concentration in Figs. $4 \mathrm{a}$ and $4 \mathrm{c}$ for two different particle Reynolds numbers $\left(R_{e^{*}}=0.1\right.$ 
and 100, respectively). It is observed that the formulas yield quite different results for the prediction of the hindered settling velocity. Consequently, the formulas also yield large differences in the prediction of $c_{m}$, and especially $c_{c r}$. In Table 1 , the results $\left(c_{m}\right.$, $c_{m} f\left(c_{m}\right)$, and $\left.c_{c r}\right)$ are presented for two different particle Reynolds numbers $\left(R_{e^{*}}=0.1\right.$ and 100 , respectively) depending on the formula used, together with an estimation based on polynomial fits over experimental data. An estimation of the error made on the estimation of $c_{m}, c_{m} f\left(c_{m}\right)$, and $c_{c r}$ is also provided.

\begin{tabular}{l|ccc|ccc} 
& \multicolumn{3}{|c|}{$R_{e^{*}}=0.1$} & \multicolumn{3}{c}{$R_{e^{*}}=100$} \\
\cline { 2 - 7 } & $c_{m} / c_{\max }$ & $\Phi\left(c_{m}\right)$ & $c_{c r} / c_{\max }$ & $c_{m} / c_{\max }$ & $\Phi\left(c_{m}\right)$ & $c_{c r} / c_{\max }$ \\
\hline experimental data & 0.29 & 0.06 & 0.52 & 0.38 & 0.10 & 0.75 \\
& \pm 0.04 & \pm 0.01 & \pm 0.07 & \pm 0.05 & \pm 0.02 & \pm 0.10 \\
\hline Richardson \& Zaki & 0.28 & 0.072 & 0.55 & 0.42 & 0.111 & 0.84 \\
\hline Souslby & 0.28 & 0.071 & 0.55 & 0.41 & 0.117 & 0.81 \\
\hline Winterwerp & 0.37 & 0.087 & 0.82 & 0.37 & 0.087 & 0.82 \\
\hline Dankers \& Winterwerp & 0.27 & 0.068 & 0.60 & 0.27 & 0.068 & 0.60 \\
\hline modified Richardson \& Zaki & 0.27 & 0.071 & 0.55 & 0.40 & 0.115 & - \\
\hline Camenen & 0.27 & 0.073 & 0.55 & 0.41 & 0.116 & 0.81
\end{tabular}

Table 1: Estimation of the $c_{m}, \Phi\left(c_{m}\right)$ and $c_{c r}$ values for non-cohesive sediments with $R_{e *}=0.1$ and $R_{e *}=100$ based on experimental data and using hindered settling formulas.

The Winterwerp (1999) and Dankers \& Winterwerp (2007) formulas (obtained for cohesive sediments) seem inaccurate for non-cohesive sediments as they do not take into account the effect of the particle Reynolds number, even though it clearly influences the results. Even for small Reynolds number, the Winterwerp formula fails to predict $c_{m}$ or $c_{c r}$ (see Tab. 1). The Dankers \& Winterwerp formula yields better results when $R_{e *}=0.1$ although it slightly overestimates $c_{c r}$. Moreover, the Winterwerp and Dankers \& Winterwerp formulas, as well as the Richardson \& Zaki and Soulsby formulas, yield a flux density function $\Phi>0$ when $c=c_{\text {max }}$, whereas it should be zero.

The Souslby formula (1997, p.135-136), modified Richardson \& Zaki formula and Camenen formula based on mixture theory (Camenen, 2008) yield very similar results, all implying that $c_{m}$ and $c_{c r}$ do vary with the particle Reynolds number. They show, however, different behaviour for large concentrations close to $c_{\max }$ : the Soulsby formula tends to overestimate the flux as it yields $\Phi>0$ when $c=c_{\text {max }}$; for relatively high particle Reynolds number $\left(R_{e^{*}}>100, c f\right.$. Figs. 4d and 5), the modified Richardson \& Zaki yields no value for $c_{c r}$, whereas for relatively low particle Reynolds number, it yields two values for $c_{c r}$ (as observed by Shannon et al., 1964); the Camenen formula yields a function $F=0$ when $c=c_{\max }(c f$ tangential to the line $y(c)=0)$, which seems to disagree with experimental 
data.

In Fig. 5, $c_{m}$ and $c_{c r}$ were estimated using the Richardson \& Zaki, modified Richardson \& Zaki, Soulsby, and Camenen formulas as well as experimental data. Results based on experimental data were obtained using polynomial fits over data points ( $c f$. Fig. 3). For small $R_{e *}, c_{m}$ is less than $0.3 c_{\max }$, and increases to $0.4-0.5 c_{\max }$ at higher $R_{e *}$. The four formulas are in good agreement with experimental estimations. A slight dispersion occurs depending on the formula for large particle Reynolds numbers. For small $R_{e *}, c_{c r}$ is less than $0.55 c_{\max }$, and increases to $0.9 c_{\max }$ at higher $R_{e *}$. The modified Richardson \& Zaki formula predicts a second value for $c_{c r}$ (called $c_{c r, 2}$ ) for low $R_{e *}$ which decreases from $0.95\left(R_{e *} \ll 1\right)$ to 0.85 at a critical particle Reynolds number $\mathfrak{R}_{*, c r} \approx 50$. Above this critical value, no solution exist for $c_{c r}$, which means that the modified Richardson \& Zaki formula will always result in the occurrence of two interfaces in a settling suspension, whatever the initial concentration. Again, the four formulas are in good agreement with experimental estimations when $R_{e *}<200$. For $R_{e *}>200$, it is difficult to conclude as there are large uncertainties on the experimental estimation; $c_{c r}$ was actually not always observed depending on the polynomial fit.

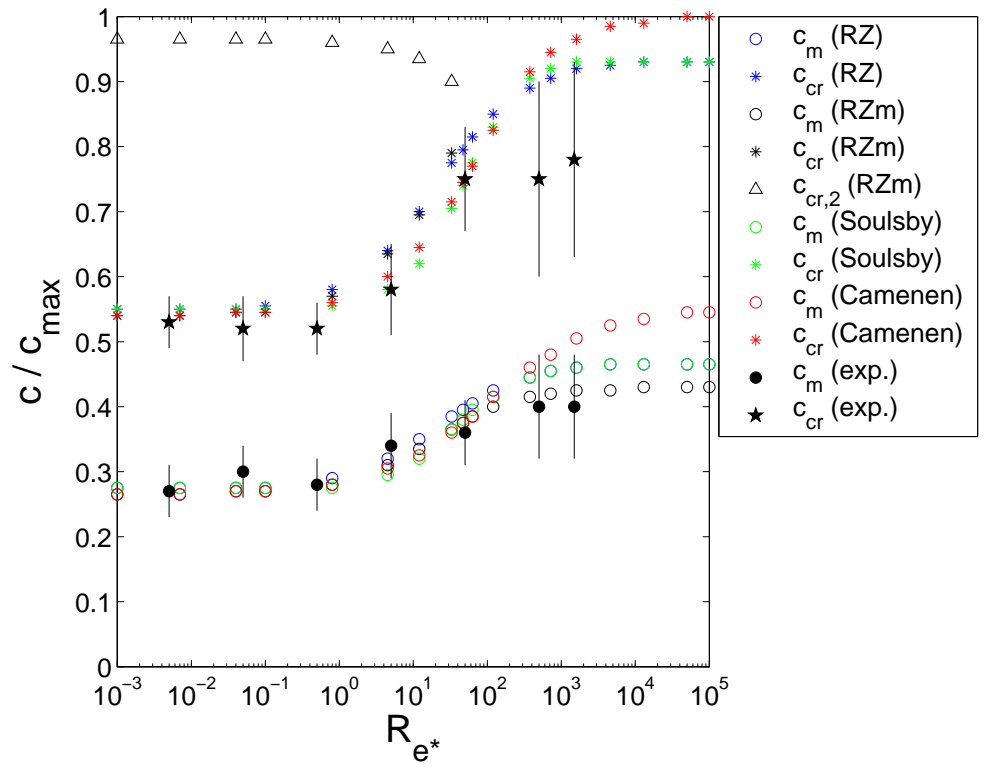

Figure 5: Concentrations $c_{m}$ and $c_{c r}$ as a function of the particle Reynolds number using the Richardson \& Zaki (RZ), modified Richardson \& Zaki (RZm), Soulsby, and Camenen formulas as well as experimental results (cf. Fig. 3).

The study of the sediment flux functions for sedimentation experiment with noncohesive sediment showed interesting results about formulas performances. For the prediction of typical parameters such as $c_{m}$ and $c_{c r}$, the Richardson \& Zaki, modified Richardson 
\& Zaki, Soulsby, and Camenen formulas yield the best results. The two latest formulas also show a better behaviour for the sediment flux close to the maximum concentration $c_{\max }$.

\subsection{Cohesive sediments}

Batch theory is not exactly applicable to cohesive suspensions, because they correspond to a population of sediments with varying size, density and shape. Moreover, as a floc is made of sediment matter and water, the volumetric concentration $c$ does not properly describe the floc volumes. Assuming that this population may be represented by a single particle with fixed characteristics, Kranenburg (1992) applied Eq. 2 to the volumetric concentration of flocs $\phi\left(\phi=\left(\rho_{s}-\rho\right) /\left(\rho_{f}-\rho\right) c\right.$, where $\rho, \rho_{s}$, and $\rho_{f}$ are the water, sediment, and flocs densities, respectively), and rewrote the equation as follows:

$$
\begin{aligned}
& \frac{\partial \phi}{\partial t}+W_{s 0} F(\phi) \frac{\partial \phi}{\partial z}=0 \\
& F(\phi)=\frac{\partial[\phi f(\phi)]}{\partial \phi}
\end{aligned}
$$

where $f(\phi)=W_{s h} / W_{s 0}$.

Eq. 8 may be solved by integrating along the characteristic lines $d z / d t=W_{s} F(\phi)$ as for the non-cohesive sediments case. In the same way as for the non-cohesive sediments, the function $F$ may have a minimum at $\phi=\phi_{c r}$. For $\phi<\phi_{c r}, d F / d \phi<0$, two interfaces will also develop ( $c f$. Fig. 6a). For $\phi>\phi_{c r}, d F / d \phi>0$, only the upper interface is visible (cf. Fig. 6b). One main difference with sand is that cohesive particles are deformable. It explains why $\phi_{\max }>c_{\max }(c f$. Camenen, 2008). First, water is ejected from pore space only $\left(0.6 \lesssim \phi<\phi_{\max }\right)$. When the gelling concentration is reached $\left(\phi=\phi_{\max } \approx 0.85\right.$ when $c=c_{g e l}$ ) and consolidation begins, the volumetric concentration of flocs ceases to increase; the floc density $\rho_{f}$ increases, and so, the volumetric concentration of matter increases $\left(c_{\text {gel }}<c_{\text {bed }, 1}<c_{\text {bed, } 2}<c_{\text {bed }, 3}<c_{\text {max }}\right)$.

In Fig. 7, flux density functions $\phi f$ and $F$ are plotted versus $\phi / \phi_{\max }$ using the formulas considered earlier, and using a typical particle Reynolds number for cohesive sediments : $R_{e^{*}}=0.1$. For all of the following tests, a constant gelling concentration $C_{g e l}=100 \mathrm{~g} / \mathrm{l}$ (or $c_{\text {gel }}=0.038$ ) was assumed, however, this value may also vary with the particle Reynolds number. The maximum volumetric concentration of flocs $\phi_{\max }$ was set to 0.85 . Following Camenen (2008), the reference formula was the modified Richardson \& Zaki. For cohesive sediments, assuming the size and density of the floc to be constant, and $n>2$, Eq. 7 may be modified as :

$$
\frac{W_{s}}{W_{s 0}}=(1-c)^{n / 2}(1-\phi)^{n / 2-1}\left(1-\frac{\phi}{\phi_{\max }}\right)^{\phi_{\max }}
$$


(a)

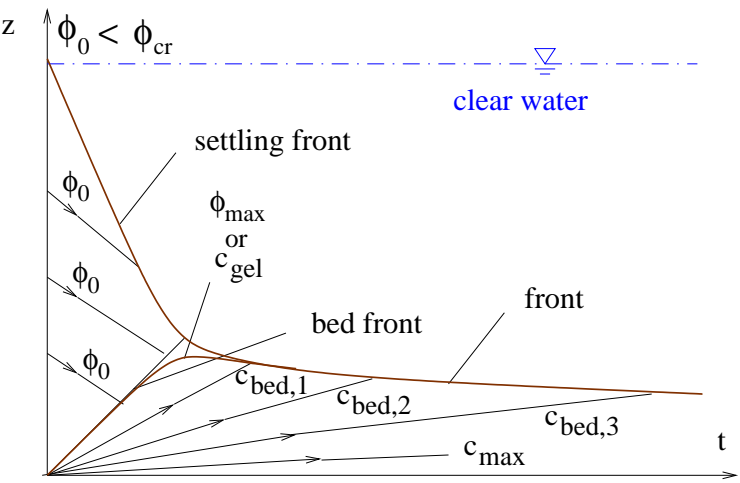

(b)

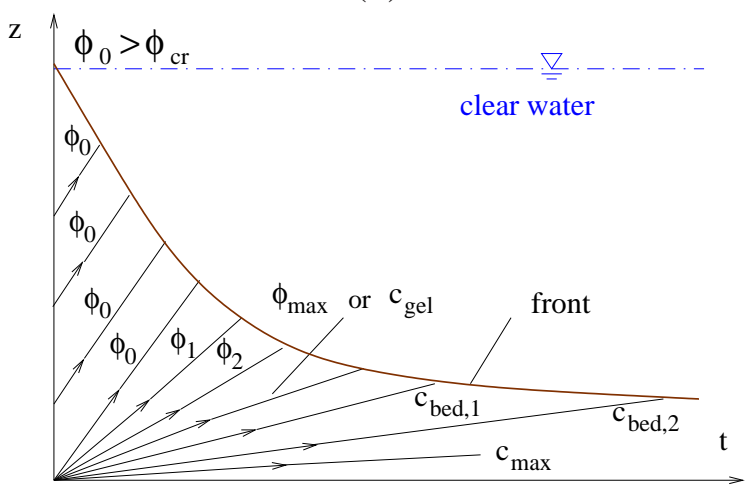

Figure 6: Schematic view of the development of one (b) or two (a) interfaces in the Kynch sedimentation test with cohesive sediments depending on the initial concentration $\phi_{0}$ (the lines with an arrow correspond to the iso-concentration lines with $\phi_{0}<\phi_{1}<\phi_{2}<\phi_{\max }$, and $c_{\text {gel }}<c_{\text {bed, } 1}<c_{\text {bed, }, 2}<c_{\text {bed }, 3}<c_{\max }$ ).

This differs slightly from the original suggestion (Eq. 11 in Camenen, 2008), which had a factor of $(1-c)^{n-2}$ instead of $(1-c)^{n / 2}$; Because of buoyancy effects, one should have $(1-c)^{x}$ with $x \geq 1$ whereas $n-2$ could be less than 1$)$.

(a)

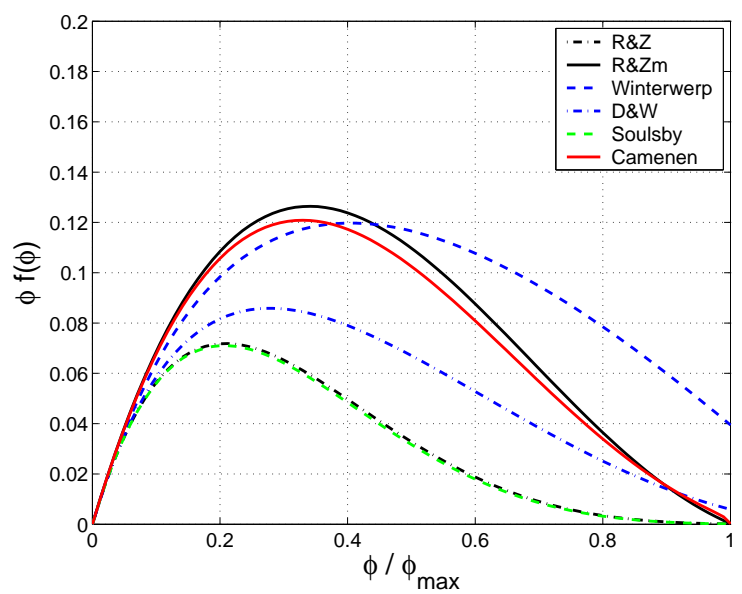

(b)

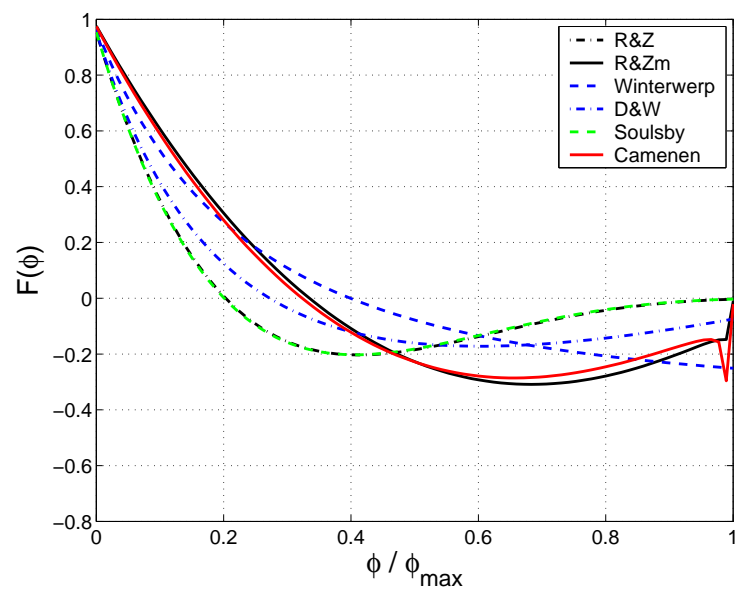

Figure 7: Variation of the flux density functions $\phi f$ (a) and $F$ (b) with the relative concentration $\phi / \phi_{\max }$ using various formulas and assuming $R_{e *}=0.1$ and a constant gelling concentration $C_{g e l}=100 \mathrm{~g} / \mathrm{l}$ for all the tests.

In Table 2, the results $\left(\phi_{m}, \phi_{m} f\left(\phi_{m}\right)\right.$, and $\left.\phi_{c r}\right)$ are presented for $R_{e *}=0.1$ depending on the formula used, together with an estimation based on polynomial fits over experimental data. An estimation of the error made on the estimation of $\phi_{m}, \phi_{m} f\left(\phi_{m}\right)$, and $\phi_{c r}$ is also provided. 


\begin{tabular}{l|ccc} 
& $\phi_{m} / \phi_{\max }$ & $\Phi\left(\phi_{m}\right)$ & $\phi_{c r} / \phi_{\max }$ \\
\hline experimental data & $0.40 \pm 0.10$ & $0.18 \pm 0.10$ & $0.75 \pm 0.15$ \\
\hline Richardson \& Zaki & 0.20 & 0.072 & 0.41 \\
\hline Souslby & 0.20 & 0.071 & 0.40 \\
\hline Winterwerp & 0.40 & 0.120 & 1.16 \\
\hline Dankers \& Winterwerp & 0.27 & 0.086 & 0.60 \\
\hline modified Richardson \& Zaki & 0.33 & 0.126 & 0.68 \\
\hline Camenen & 0.32 & 0.121 & 0.66
\end{tabular}

Table 2: Estimation of the $\phi_{m}, \Phi\left(p h i_{m}\right)$ and $p h i_{c r}$ values for cohesive sediments with $R_{e^{*}}=0.1$ based on experimental data and using hindered settling formulas.

The Soulsby and the Richardson \& Zaki equations yield similar results as both equations include the effect of the hindered settling velocity using a coefficient $(1-\phi)^{n}$ with $n \approx 4.7$ for small $R_{e *}$. These minimize $F$ at $\phi_{c r}=2 /(n+1)$ (cf. Eq. 6), i.e. $\phi_{c r} \approx 0.4 \phi_{\max }$ for fine sediments, which appears to be too low. Both equations underestimate $\Phi$-values as they underestimate the settling velocity (Camenen, 2008). The Winterwerp, modified Richardson \& Zaki and Camenen relationships behave similarly for the function $f$ at low volumetric concentrations $\left(\phi / \phi_{\max }<0.5\right)$. As the Winterwerp formula does not take into account the possibility that $\phi_{\max }<1$ (the assumption $\phi_{\max }=1$ is stated), it yields a larger flux for large concentrations. However, a different calibration of $C_{g e l}$ for the Winterwerp formula would produce estimates similar to Richardson \& Zaki and Camenen relationships. On the other hand, it does not yield any minimum for the function $F$, and thus will always predict the existence of two interfaces in a settling suspension. Dankers \& Winterwerp proposed a modification that improved this behaviour and derived a minimum for the function $F$. However, this modification significantly decreased the magnitude of the density function.

To confirm these results, experimental data obtained with cohesive sediments were analysed (Thorn, 1981; Ross, 1988; Wolanski et al., 1989, 1992; Mory et al., 2002; Gratiot, 2004; and Dankers et al., 2005). All of these studies used natural mud with the exception of the Wolanski et al. (1989) and Dankers et al. (2005) data sets (kaolinite) and one data set from Mory et al. (2002) where the mud was pretreated. In the case of cohesive sediments, large uncertainties occur as the size and density of the floc cannot be measured accurately and because these values represent a statistical measure of a population. In dilute suspensions, the size (and the density) of the floc varies with the concentration (due to flocculation). It is assumed that the floc characteristics (size and density) did not change during the sedimentation experiments, and were identical to the flocs at the maximum concentration, below which hindered effects were not observed $(C \approx 5$ to 10 
$\mathrm{g} / \mathrm{l}$ ). The assumption of a constant mean floc size may be justified since the flocculation effects (increase of the mean size of the flocs with concentration) may be balanced by the concentration effects (decrease of the mean size of the flocs with concentration due to floc breakup). The density of the floc is then calculated using the estimated gelling concentration, i.e. $\rho_{f}=\rho+\left(\rho_{s}-\rho\right) c_{\text {gel }} / \phi_{\max }$ (with $\phi_{\max }=0.85$ ). This latter was evaluated to maximize the fit to experimental data points $\left(C_{g e l}\right.$ varying from from $30 \mathrm{~g} / \mathrm{l}$ to $90 \mathrm{~g} / \mathrm{l}$ depending on the data set), with the exception of the Dankers et al. data set, where the gelling concentration $\left(C_{g e l} \approx 85 \mathrm{~g} / \mathrm{l}\right)$ was estimated experimentally.

In Fig. 8, the flux density function $\left(\Phi / W_{s 0}=\phi f\right)$ is plotted versus the relative concentration $\phi / \phi_{\max }$ using the data collected for cohesive sediments, with particle Reynolds number $R_{e *}$ emphasized. The results show a lot of scatter due to experimental uncertainties (including estimation of gelling concentration) and the variability in floc characteristics, as they were assumed constants. The data corresponding to $\phi>\phi_{\max }$ should correspond to the consolidation regime. As data points are based on volumetric concentration of matter $c$, physically unrealistic values of $\phi$ are observed in Fig. 8 when $c>c_{g e l}$ as $\phi$ should be lower than $\phi_{\max }$. When $c>c_{\text {gel }}, \phi=\phi_{\max }$ but the floc density increases as water is expelled from the floc. It is difficult to determine the influence of the particle Reynolds number from these experimental results, because of the scatter in the data and also because they cover a narrow range of particle Reynolds numbers $\left(2 \times 10^{-2}<R_{e *}<2\right)$. Using polynomial fits over data sets, $\phi_{m}$ and $\phi_{c r}$ were approximated (see also Tab. 2 and Fig. 9) and a rough estimation of $\phi_{m}$ and $\phi_{c r}$ may be suggested : $0.2<\phi_{m} / \phi_{\max }<0.4$ and $0.6<\phi_{c r} / \phi_{\max }<0.8$, which confirms the results from the modified Richardson \& Zaki, Camenen, and Dankers $\&$ Winterwerp formulas. Using a particle Reynolds number $R_{e_{*}}=0.2$ (median values of the collected data) and $C_{g e l}=100 \mathrm{~g} / \mathrm{l}$, the curves obtained from the modified Richardson \& Zaki, Camenen and Dankers \& Winterwerp equations are plotted together with the data in Fig. 8. As observed before, the Dankers \& Winterwerp formula seems to underestimate values for flux density.

The Winterwerp and Dankers \& Winterwerp formulas also yield a constant value for $\phi_{m}$ and $\phi_{c r}$, no matter what the particle Reynolds number is (see Tab. 2). Dankers et al. (2005) found from observations in their settling column (where $C_{g e l}=85 \mathrm{~g} / 1$ and $R_{e^{*}}=3 \times 10^{-2}$ ) and by comparing the rising bed in the concentration time series, that the settling behaviour changed for $0.53<\phi_{c r}<0.55$, which means $\phi_{c r} / \phi_{\max } \approx 0.68$. These values are consistent with results of the modified Richardson \& Zaki and Camenen equations $\left(\phi_{c r} \approx 0.6-0.7 \phi_{\max }, c f\right.$. Tab. 2$)$.

In Fig. 9, $\phi_{m}$ and $\phi_{c r}$ were estimated using the Richardson \& Zaki, modified Richardson \& Zaki, Soulsby, and Camenen formulas as well as experimental data. Results based on experimental data were obtained using polynomial fits over data points when possible (cf. Fig. 8). The $\phi_{m}$ and $\phi_{c r}$ values vary significantly among empirical formulas. The sen- 


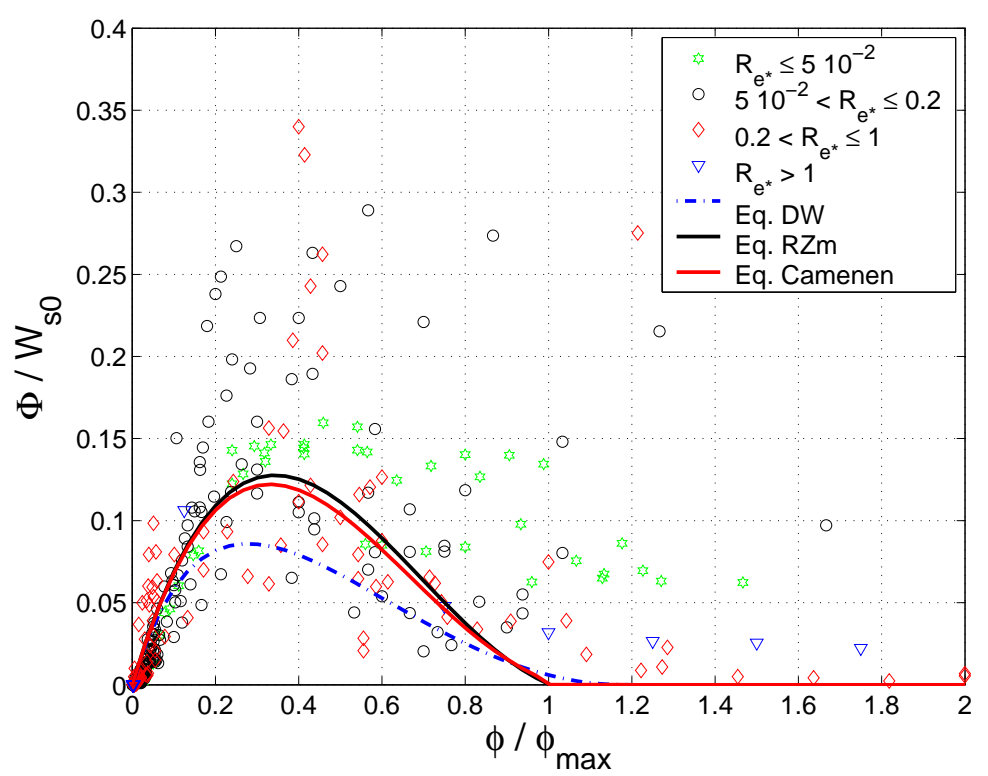

Figure 8: Flux density function $\left(\Phi / W_{s 0}=\phi f\right)$ as a function of the relative concentration $\phi / \phi_{\max }$ using the collected data for cohesive sediments with the particle Reynolds number $R_{e *}$ emphasized.

sitivity to the particle Reynolds number is therefore not as strong as for the non-cohesive sediments. If the Richardson \& Zaki and Souslby formulas yield similar results as for noncohesive sediments (the differences only correspond to the ratio $c_{\max } / \phi_{\max }$ ), the modified Richardson \& Zaki and Camenen formulas yield much larger values (50\% larger for both $\phi_{m}$ and $\phi_{c r}$ ). Experimental data although scattered indicate that the Richardson \& Zaki and Souslby formulas significantly underestimate the $\phi_{m}$ and $\phi_{c r}$-values. The sensitivity to the gelling concentration $\left(C_{g e l}=50 \mathrm{~g} / \mathrm{l}, C_{g e l}=100 \mathrm{~g} / 1, C_{g e l}=200 \mathrm{~g} / \mathrm{l}\right.$ and $C_{g e l}=500 \mathrm{~g} / \mathrm{l}$ were tested for a fixed particle Reynolds number) appears to be negligible for the relationship between $\phi_{m}$ or $\phi_{c r}$ and $R_{e *}$. An increasing gelling concentration tends to slightly decrease $\phi_{m}, \phi_{m} f\left(\phi_{m}\right)$, and $\phi_{c r}$. This may be explained as all these equations, as well as $\phi_{m}$ or $\phi_{c r}$, are mainly function of $\phi$, independantly of $C_{g} e l$, and are plotted versus $\phi$. In the same way as for non-cohesive sediments, no solution is found for the modified Richardson \& Zaki and Camenen formulas for $d F / d c=0\left(\phi_{c r}\right)$ when $R_{e *}>70$ and $R_{e *}>200$, respectively (cf. Fig. 9b). For typical cohesive sediments where $R_{e *}<1, \phi_{m}$ and $\phi_{c r}$ do not vary significantly with the particle Reynolds number. The Winterwerp formula thus yields coherent results for $\phi_{m}\left(\phi_{m}=0.390 \phi_{\max }\right)$. The Winterwerp formula, modified by Dankers $\&$ Winterwerp also estimates reasonable values for $\phi_{c r}$ and $\phi_{m}$, although they appear slightly underestimated $\left(\phi_{m}=0.270 \phi_{\max }\right.$ and $\left.\phi_{c r}=0.600 \phi_{\max }\right)$.

The study of the sediment flux functions for sedimentation experiment with cohesive sediment showed interesting results about formulas performances although experimental 
(a)

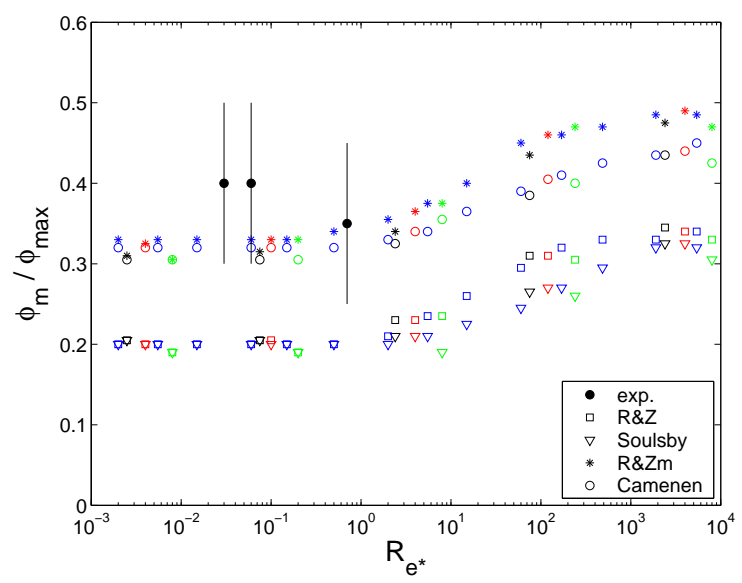

(b)

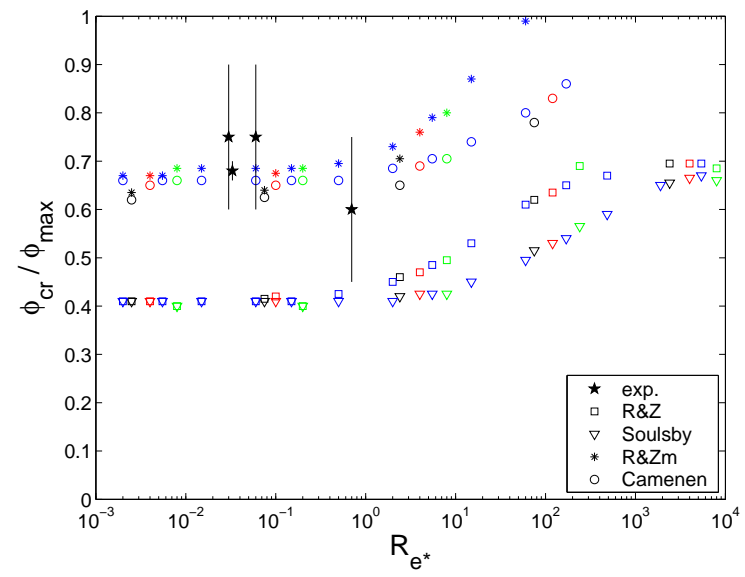

Figure 9: Concentration $\phi_{m}$ (a) and $\phi_{c r}$ (b) as a function of the particle Reynolds number using the Richardson \& Zaki (RZ), Souslby, modified Richardson \& Zaki (RZm), and Camenen formulas.

results do not allow any conclusion on the influence of particle Reynolds number. For the prediction of typical parameters such as $\phi_{m}$ and $\phi_{c r}$, the modified Richardson \& Zaki, Dankers \& Winterwerp, and Camenen formulas yield the best results.

\section{Permeability regime}

As proposed by Toorman $(1996,1999)$ and also Winterwerp (1999), the initial phase of the consolidation regime (ejection of pore water) may be included in the 1D equation for sedimentation through the total settling velocity function $W_{s k}(c f$. Eqs. 1 and 2). The difficulty lies in determining the permeability of mud.

\subsection{Estimation of the permeability}

Many relationships have been proposed to estimate permeability. Permeability is often a function of the void ratio $e_{v r}=1 / c-1$. Among others, Townsend \& McVay (1990) used a power law relationship ( $c f$. Eq. 11) whereas Bartholomeeusen (2003) used an exponential function (cf. Eq. 12) :

$$
\begin{aligned}
k & =A_{k p} e_{v r}^{B_{k p}} \\
k & =A_{k e} \exp \left(B_{k e} e_{v r}\right)
\end{aligned}
$$

Both formulations, however, require the calibration of two coefficients. It should also be noted that these relations (Eqs. 11 and 12) are mainly empirical and derived from data where effective stress are expressed in $\mathrm{kPa}$ or even $\mathrm{MPa}$ (far from the permeability regime 
defined in section 2.1). Merckelbach (2000) and Merckelbach \& Kranenburg (2004) suggested a fractal approach to estimate permeability, and their formulation includes the effect of sand content :

$$
k=A_{k f}\left(\frac{c_{\text {mud }}}{1-c_{\text {sand }}}\right)^{-\frac{2}{3-n_{f}}}
$$

where $c_{\text {mud }}$ and $c_{\text {sand }}$ are the volumetric concentrations for mud and sand, respectively $\left(c_{\text {mud }}=\left(1-p_{\text {sand }}\right) c\right.$ and $c_{\text {sand }}=p_{\text {sand }} c$ where $p_{\text {sand }}$ is the sand content (in \%) and $c$ is then the total volumetric concentration of matter), and $n_{f} \leq 3$ is the fractal dimension. When sand content is negligible, $c_{\text {mud }} /\left(1-c_{\text {sand }}\right) \approx c$. The degree to which permeability depends on concentration may be indicated by $n_{f}$. The coefficient $A_{k f}\left(A_{k p}\right.$ or $\left.A_{k e}\right)$ remains to be determined.

Bartholomeeusen et al. (2002) made a prediction exercise (named "Sidere"), using a batch of sediments from the river Scheldt (Antwerpen, Belgium). The grain size distribution were given approximately by the parameters $d_{10}, d_{50}, d_{90}$, equal to 6,70 , and $210 \mu \mathrm{m}$, respectively, with a specific gravity equal to $s=2.72$. Different experiments were performed with an initial density $1300<\rho_{\text {mix,init }}<1550 \mathrm{~kg} / \mathrm{m}^{3}$ greater than the structural density, which corresponds approximately to a gelling concentration $c_{\text {gel }} \approx 0.1$ 0.15. Several scientists (Bartholomuseeusen, Carrier, Lin \& Penumadu, Masada \& Chan, Merckelbach, Van Kesteren, Winterwerp, and Znidarcic; $c f$. Bartholomeeusen et al., 2002 for details) calibrated their own model using the same experimental data ( $c f$. Fig. 10). Though large differences were observed for the calibration of the coefficients " $A$ " and " $B$ " depending on the specific formulations used (Eq. 11, 12 or 13, see also Bartholomeeusen et al., 2002), similar results were observed when $0.2<c<0.5$, i.e. $c_{\text {gel }}<c<4 c_{\text {gel }}$, which corresponds to the limit of validity of the present model (consolidation included as a sedimentation effect). However, one can observe in Fig. 10 that all these formulas yield a large variability in the results when $c \approx c_{\text {gel }}$.

To fit Eqs. 11,12, and 13 to the data requires the estimation of two coefficients with significant risks of disconnection with the settling characteristics of the sediment. One way to estimate the permeability coefficients may be to use the hindered settling characteristics of the sediment since the permeability function reads $W_{k}=(s-1) k c$ (where $s=\rho_{s} / \rho$ is the relative density of matter). Eq. 13 with $p_{\text {sand }}=0 \%$ gives $k=A_{k} c^{B_{k}}$ (with $B_{k}=-2 /\left(3-n_{f}\right)$ ). Fixing $B_{k}$, it is possible to find a concentration $c=c_{g e l} / \chi$ (with $\chi$ a fixed parameter to be calculated, $\chi>1$ ) such that the slope of the hindered velocity function is the same as the permeability function, i.e. $d\left\{\log \left(W_{s h}\right)\right\} / d c=d\left\{\log \left(W_{k}\right)\right\} / d \log (c)=B_{k}+1$. The parameter $A_{k}$ is determined from the relationship $W_{k}\left(c=c_{g e l} / \chi\right)=(s-1) k\left(c=c_{g e l} / \chi\right) c_{g e l} / \chi$. Then, 


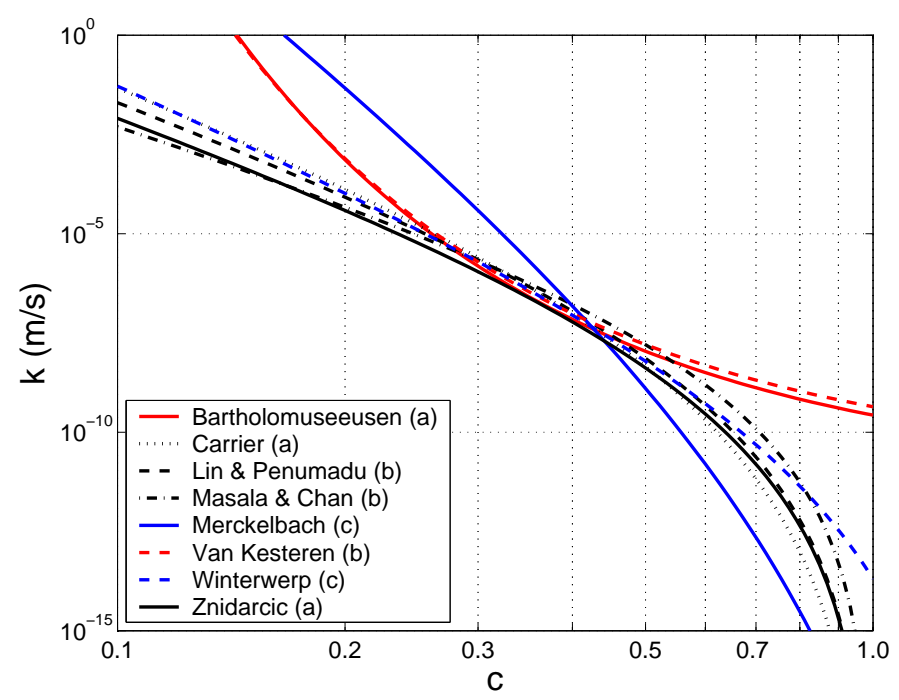

Figure 10: Estimation of the permeability $k$ as a function of the concentration $c$ using various empirical formulas calibrated by several scientists for the "Sidere" exercice ((a) refers to Eq. 11; (b) to Eq. 12 and (c) to Eq. 13).

for $c>c_{g e l} / \chi$, we obtain :

$$
k=\frac{W_{s h}\left(c=c_{g e l} / \chi\right)}{(s-1) c_{g e l} / \chi}\left[\frac{c}{c_{g e l} / \chi}\right]^{B_{k}}
$$

\subsection{Total settling function}

As hindered settling functions yield $W_{s}=0$ when $c \geq c_{\text {gel }}$ and permeability functions (Eqs. 11,12, and 13) cannot be linked to the settling velocity when $c \leq c_{g e l}$, Winterwerp (1999) suggested defining a fitting function to obtain an unique equation for $W_{s k}$ :

$$
W_{s k}=W_{s h}+\frac{(s-1) k c}{1+\xi(s-1) k c}
$$

with $\xi \approx 10^{4}-10^{5}$ being a heuristic parameter to obtain a smooth transition between the descriptions for the hindered settling regime and the permeability regime ( $c f$. Fig. 11).

Using Eq. 14, a second method to compute the total settling function may be suggested :

$$
W_{s k}= \begin{cases}W_{s h} & \text { if } c \leq \frac{c_{g e l}}{\chi} \\ W_{k}=W_{s h}\left(c=c_{g e l} / \chi\right)\left[\frac{\chi c}{c_{g e l}}\right]^{B_{k}+1} & \text { if } c>\frac{c_{g e l}}{\chi}\end{cases}
$$


(a)

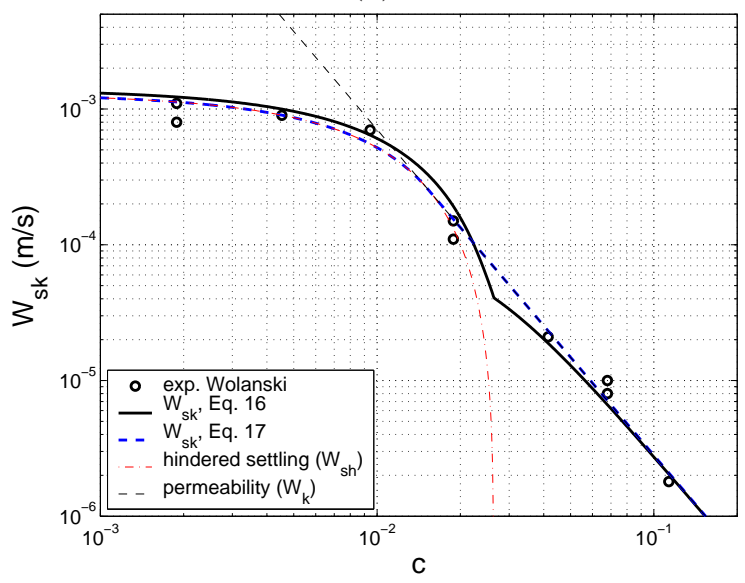

(b)

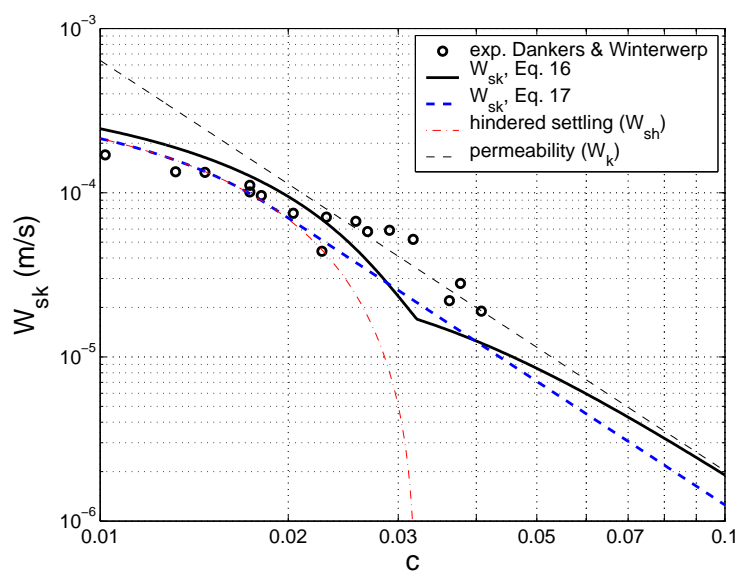

Figure 11: Estimation of the total settling velocity function $W_{s k}$ (based on Eq. 15 or on Eq. 16) compared to experimental data (a) from Wolanski et al. $\left(1989 ; C_{g e l}=70 \mathrm{~g} / 1, A_{k}=7 \times 10^{-9}, B_{k}=3.4\right.$, and $\left.\xi=1 \times 10^{4}\right)$ and (b) from Dankers \& Winterwerp (2007; $C_{\text {gel }}=85 \mathrm{~g} / 1, A_{k}=4 \times 10^{-9}, B_{k}=3.5$, and $\left.\xi=3 \times 10^{4}\right)$.

Estimates of the total settling velocity function $W_{s k}$ are presented in Fig. 11 and are compared to experimental data (a) from Wolanski et al. (1989) and (b) from Dankers \& Winterwerp (2007). For both cases, Eq. 10 has been plotted versus data (after an estimation of $W_{s 0}$ and $c_{g e l}$ ) as well as $W_{k}$ based on Eq. 13 (with $p_{\text {sand }}=0 \%$ ) and fitted with the experimental data (fit of the coefficients $A_{k}$ and $B_{k}$ ). The total settling function $W_{s k}$ was then plotted using Eqs. 15 and 16. For Eq. 16, a second equation for the permeability function was estimated by using Eq. 14 with the same slope $B_{k}$ as for $W_{k}$.

If $W_{k}>W_{s h} \forall c$ ( $c f$. Fig. 11b), both equations yield unsatisfactory results. The Winterwerp method tends to overestimate results for the hindered settling regime. On the other hand, the present method tend to underestimate results for the permeability regime. On the other hand, if the $W_{k}$ function intersects the $W_{s h}$ function ( $c f$. Fig. 11a), both equations yield satisfactory results. Eq. 15 does however induce a discontinuity in the slope $d W_{s k} / d c$ at $c=c_{g e l}$ which seems to be unrealistic. Indeed, in reality, because of the variability of the cohesive particles in the suspension, the consolidation regime may start locally before the concentration reaches its gelling point (which is defined globally). As shown in Fig. 11 , data points present a smooth transition between the hindered regime and the permeability regime, which is not reproduced by Eq. 15. Moreover, Eq. 15 needs to fit three parameters $\left(A_{k}, B_{k}\right.$, and $\left.\xi\right)$ whereas Eq. 16 needs to fit only one parameter $\left(B_{k}\right)$.

It is important to realize how the use of the total settling velocity function influences sedimentation dynamics. In Fig. 12, the flux density functions $F$ (calculated using total settling velocity function $W_{s k}$ based on Eq. 15 or on Eq. 16 fitted with the experimental 
data of Dankers \& Winterwerp, see also Fig.11) have been plotted versus the relative concentration $\phi / \phi_{\max }$. It appears that Eq. 16 induces a slight decrease of the value for $\phi_{c r}$ compared to the original formula for the hindered settling (Eq. 10). On the other hand, Eq. 15 yields a discontinuity in the function $F$ for $\phi=\phi_{\max }=\phi_{\text {gel }}$ with a change in the sign of $d F / d \phi$. Following the study of Concha \& Bürger (2002), it yields an interface for $\phi=\phi_{\max }=\phi_{g e l}$, which does not seem to be physically realistic.

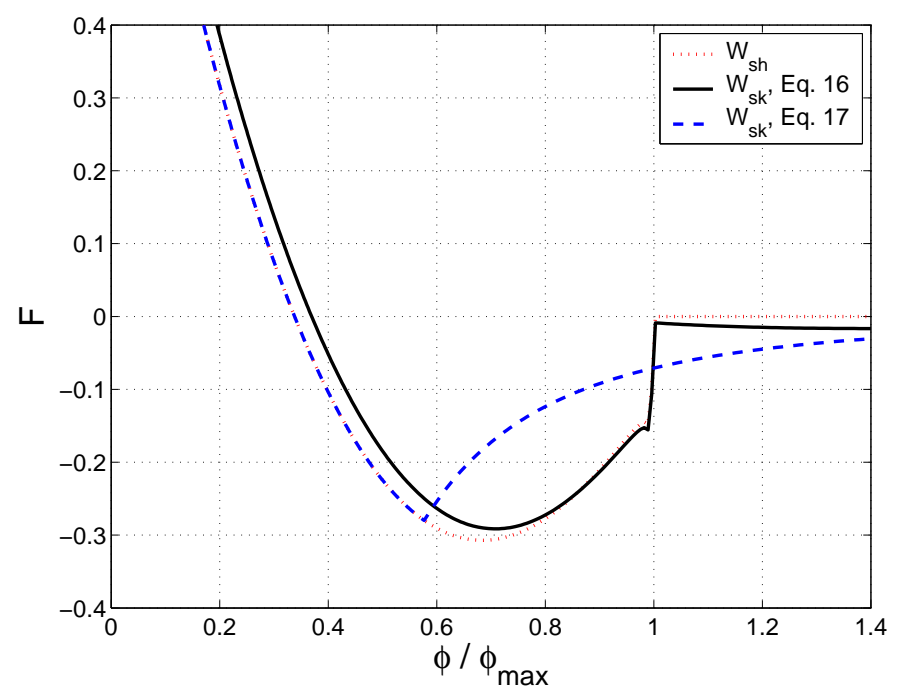

Figure 12: Variation of the flux density function $F$ with the relative concentration $\phi / \phi_{\max }$. The flux density function is calculated using total settling velocity function $W_{s k}$ based on Eq. 15 or on Eq. 16 fitted with the experimental data of Dankers \& Winterwerp, see also Fig.11b)

\section{Conclusions}

The effect of the hindered settling formula on predicting sedimentation has been presented. For non-cohesive sediments, the particle Reynolds number strongly affected estimates of the critical concentrations $c_{m}$, where the flux reaches a maximum, and $c_{c r}$, above which only one interface will be observed during a batch experiment (if $c_{0}>c_{c r}$ ). For cohesive sediments, as the particle Reynolds number is generally smaller than 1 , the effect of $R_{e *}$ was not as significant. One main difficulty remains in determining the gelling concentration. The modified Richardson \& Zaki formula suggested by Camenen (2008) appeared to yield the best overall results among the studied formulas compared to the experimental data, i.e. the best representation of the density function for both non-cohesive $\left(c_{m}, \Phi\left(c_{m}\right)\right.$, and $\left.c_{c r}\right)$ and cohesive $\left(\phi_{m}, \Phi\left(\phi_{m}\right)\right.$, and $\left.\phi_{c r}\right)$ sediments. However, the valida- 
tion with cohesive experimental data remains difficult because of the uncertainties and the inherent variability of cohesive sediments.

Several propositions for the estimation of permeability were also discussed for concentrations two to three times larger than the gelling concentration. A fundamental issue, which is the link between the hindered regime and the permeability regime, was discussed. It appeared preferable to obtain a relationship for $W_{s k}$ that remains smooth at $c=c_{g e l}$ to avoid prediction of a physically unrealistic interface at this concentration. A solution was suggested using a permeability function that is tangential to the hindered settling function.

Many uncertainties remain in the description of cohesive sediments, hindered settling velocities and consolidation of cohesive sediments : i.e. the influence of organic content and flocculation, the interaction between particles of different sizes (as muds often have a large particle size distribution), and sediment history for consolidation. The model proposed in this paper suggests some improvements compared to the existing literature. Some efforts are still needed to better understand the dynamics of suspensions close to the gelling concentration, and to be able to represent them in a relatively simple way hat could be applicable in engineering models.

\section{Acknowledgement}

The manuscript improved considerably as a result of comments by two unknown reviewers (\#1 and \#3) and by the guest-editor (R. Verney).

\section{References}

Baldock, T., Tomkins, M., Nielsen, P., Hugues, M., 2004. Setting velocity of sediments at high concentrations. Coastal Eng. 51, 91-100.

Bartholomeeusen, G., 2003. Compound shock waves and creep behaviour in sediment beds. Ph.D. thesis, University of Oxford.

Bartholomeeusen, G., Sills, G., Znidarcic, D., Van Kesteren, W., Merckelbach, L. M., Pyke, R., Carrier III, W. D., Lin, H., Penumadu, D., Winterwerp, H., Masala, S., Chan, D., 2002. Sidere: numerical prediction of large-strain consolidation. Géotechnique 52 (9), 639-648.

Been, K., Sills, G., 1981. Self-weight consolidation of soft soils: an experimental and theoretical study. Géotechnique 31 (4), 519-535.

Camenen, B., 2007. Simple and general formula for the settling velocity of particles. J. Hydraulic Eng. 133 (2), 229-233. 
Camenen, B., 2008. Settling velocity of sediments at high concentrations. In: Kusuda, T., Yamanishi, H., Spearman, J., Gailani, J. (Eds.), Sediment and Ecohydraulics: Intercoh 2005. Vol. 9 of Proceedings in Marine Science. Elsevier, pp. 211-224, (Proceedings from Intercoh conference, Saga, Japan, 2005).

Concha, F., Bürger, R., 2002. A century of research in sedimentation and thickening. KONA 20, 38-70.

Dankers, P., Winterwerp, J., 2007. Hindered settling of mud flocs: theory and validation. Continental Shelf Res. 27, 1893-1907.

Dankers, P., Winterwerp, J., Van Kesteren, W., 2005. A preliminary study on the hindered settling of kaolinite flocs. In: Maa, J., Sandford, L., Schoellhamer, D. (Eds.), Estuarine and coastal fine sediment dynamics: Intercoh 2003. Vol. 8 of Proceedings in Marine Science. Elsevier, pp. 221-235, (Proceedings from Intercoh conference, Gloucester Point, Virginia, USA, 2003).

Dyer, K., Manning, A., 1999. Observation of the size, settling velocity and effective density of flocs, and their fractal dimensions. J. Sedimentary Res. 41, 87-95.

Gibson, R., England, G., Hussey, M., 1967. The theory of onedimensional consolidation of saturated clays. i. finite nonlinear consolidation of thin homogeneous layers. Géotechnique 17, 261-273.

Gratiot, N., 2004. Floculation des vases de gironde: mesure experimentale du flux de chute en colonne, (inner report for IRD, in French).

Gratiot, N., Michallet, H., Mory, M., 2005. On the determination of the settling flux of cohesive sediments in a turbulent fluid. J. Geophysical Res. 110 (C06004).

Kranenburg, C., 1992. Hindered settling and consolidation of mud - analytical results. Tech. Rep. Report 11-92, Delft University of Technology, Dept. Civil Eng., Hydrodynamic section.

Kynch, S., 1952. A theory on sedimentation. Trans. Faraday Soc. 48, 166-176.

Mehta, A. J., 1991. Review notes on cohesive sediment erosion. In: Proc. Coastal Sediments'91. ASCE, Seattle, Washington, p. 40-53.

Merckelbach, L., 2000. Consolidation and strength evolution of soft mud layers. Communications on hydraulic and geotechnical eng., report 00-2, Delf University of Technology, Faculty of Civil Eng., ISSN 0169-6548. 
Merckelbach, L., Kranenburg, C., 2004. Equations for effective stress and permeability of soft mudÜsand mixtures. Géotechnique 54 (4), 235-243.

Mory, M., Gratiot, N., Manning, A., Michallet, H., 2002. CBS layers in a diffusive turbulence grid oscillation experiment. In: Winterwerp, J., Kranenburg, C. (Eds.), Fine sediment dynamics in the marine environment. Vol. 5 of Proceedings in Marine Science. Elsevier, pp. 139-154, (Proceedings from Intercoh conference, Delft, The Netherlands, 2000).

Oliver, D., 1961. The sedimentation of suspensions of closely-sized spherical particles. Chemical Eng. Science 15, 280-242.

Richardson, J., Zaki, W., 1954. Sedimentation and fluidisation: Part I. Trans. Instn. Chem. Engrs. 32, 35-53.

Ross, M., 1988. Vertical structure of estuarine fine sediment suspensions. Ph.D. thesis, Coastal \& Oceanographic Engineering Department, Universty of Florida, Gainsville, Florida, USA.

Rowe, P., 1987. A convenient empirical equation for estimation of the Richardson-Zaki exponent. Chemical Eng. Science 42 (11), 2795-2796.

Shannon, P., Dehaas, R., Stroupe, E., Tory, E., 1964. Batch and continuous thickening: Prediction of batch settling behavior from initial rate data with results for rigid spheres. Ind. Eng. Chem. Fundamentals 3 (3), 250-260.

Soulsby, R., 1997. Dynamics of marine sands, a manual for practical applications. Thomas Telford, London, UK, ISBN 0-7277-2584 X.

Thorn, M., 1981. Physical processes of siltation in tidal channels. In: Proc. Hydraulic Modelling Applied to Maritime Engineering Problems. ICE, London, pp. 47-55.

Toorman, E., 1996. Sedimentation and self-weight consolidation: general unifying theory. Géotechnique 46 (1), 103-113.

Toorman, E., 1999. Sedimentation and self-weight consolidation: constitutive equations and numerical modelling. Géotechnique 49 (6), 709-726.

Toorman, E., Berlamont, J., 1991. A hindered settling model for the prediction of settling and consolidation of cohesive sediment. Geo-Marine Letters 11, 179-183.

Townsend, F., Mc Vay, M., 1990. SOA: large strain consolidation prediction. J. Geotechnical Eng. 116 (2), 222-243. 
Van Leussen, W., 1988. Aggregation of particles, settling velocity of mud flocs - a review. In: Dronkers, J., Van Leussen, W. (Eds.), Physical Processes in Estuaries. Springer, pp. $345-403$.

Winterwerp, J., 1999. On the dynamics of high-concentrated mud suspensions. Ph.D. thesis, Delft University of Technology, Delft, The Netherlands, ISBN 0169-6548.

Winterwerp, J., Van Kesteren, W., 2004. Introduction to the physics of cohesive sediment in the marine environment. Vol. 56 of Developments in sedimentology. Elsevier, ISBN $0-444-51553-4$.

Wolanski, E., Asaeda, T., Imberger, J., 1989. Mixing across a lutocline. Limnology \& Oceanography 35 (5), 931-938.

Wolanski, E., Gibbs, R., Mazda, Y., Metha, A., King, B., 1992. The role of turbulence in settling of mudflocs. J. Coastal Res. 8 (1), 35-46.

\section{Appendices}

\section{A. Settling functions}

The following settling functions were used in the paper. They are written for cohesive sediments; in case of non cohesive sediments, $\phi=c$.

- Richardson \& Zaki (1954) : $f=(1-\phi)^{n}$;

- Souslby (1997) : $f=\frac{\left[10.36^{2}+1.049(1-\phi)^{4.7} d_{*}^{3}\right]^{1 / 2}-10.36}{\left[10.36^{2}+1.049 d_{*}^{3}\right]^{1 / 2}-10.36}$

where $d_{*}=[(s-1) g / v]^{1 / 3} d$ and $d$ grain diameter;

- Winterwerp (1999) : $f=\frac{(1-\phi)(1-c)}{1+2.5 \phi}$;

- Dankers \& Winterwerp (2007) : $f=\frac{(1-\phi)^{2}(1-c)}{1+2.5 \phi}$; 
- Camenen (2008) : $f=\frac{v_{m i x}}{v} \frac{\sqrt{(A / B)^{2 / N} / 4+\left(4 / 3 d_{* m i x}{ }^{3} / B\right)^{1 / N}}-(A / B)^{1 / N} / 2}{\sqrt{(A / B)^{2 / N} / 4+\left(4 / 3 d_{*}^{3} / B\right)^{1 / N}}-(A / B)^{1 / N} / 2}$

where $A, B$, and $N$ are coefficients for the settling formula, which are function of the grain shape and roundness (see Camenen, 2007; for natural sands, $A=24.6$, $B=0.96$, and $N=1.53$; for flocs, $A=27, B=2.1$, and $N=1.2$ ) and subscript ${ }_{\text {mix }}$ yields that the kinetic viscosity and density were calculated for a mixture (water + sediments).

\section{B. Table of notation}

The following symbols are used in this paper :

\begin{tabular}{|c|c|c|}
\hline$A, B$ & {$[-]$} & coefficients \\
\hline$c$ & {$[-]$} & volumetric concentration of matter \\
\hline$c_{b e d}$ & {$[-]$} & $\begin{array}{l}\text { volumetric concentration of matter in the bed for a batch ex- } \\
\text { periment }\end{array}$ \\
\hline$c_{\text {mud }}, c_{\text {sand }}$ & {$[-]$} & $\begin{array}{l}\text { volumetric concentration of matter for mud and sand, respec- } \\
\text { tively }\end{array}$ \\
\hline$C$ & {$\left[g l^{-1}\right]$} & mass concentration of matter $\left(C=\rho_{s} c\right)$ \\
\hline$d$ & {$[m]$} & sediment grain diameter \\
\hline$d_{k}$ & {$[m]$} & $\begin{array}{l}\text { sediment grain diameter for which } \mathrm{k} \% \text { of the grain by mass } \\
\text { is finer }\end{array}$ \\
\hline$D$ & {$\left[m^{2} s^{-1}\right]:$} & total dissipation coefficient \\
\hline$D_{m}$ & {$\left[m^{2} s^{-1}\right]:$} & dissipation coefficient due to molecular effects \\
\hline$D_{c}$ & {$\left[m^{2} s^{-1}\right]$} & dissipation coefficient due to consolidation-diffusion effects \\
\hline$D_{t}$ & {$\left[m^{2} s^{-1}\right]:$} & dissipation coefficient due to turbulence effects \\
\hline$e_{v r}$ & {$[-]$} & void ratio $\left(e_{v r}=1 / c-1\right)$ \\
\hline$f$ & {$[-]$} & $\begin{array}{l}\text { function corresponding to the hindering effects }(f= \\
\left.W_{s h} / W_{s 0}\right)\end{array}$ \\
\hline$F$ & {$[-]$} & $\begin{array}{l}\text { function corresponding to the hindering effects }(F= \\
\partial(f c) / \partial c)\end{array}$ \\
\hline
\end{tabular}




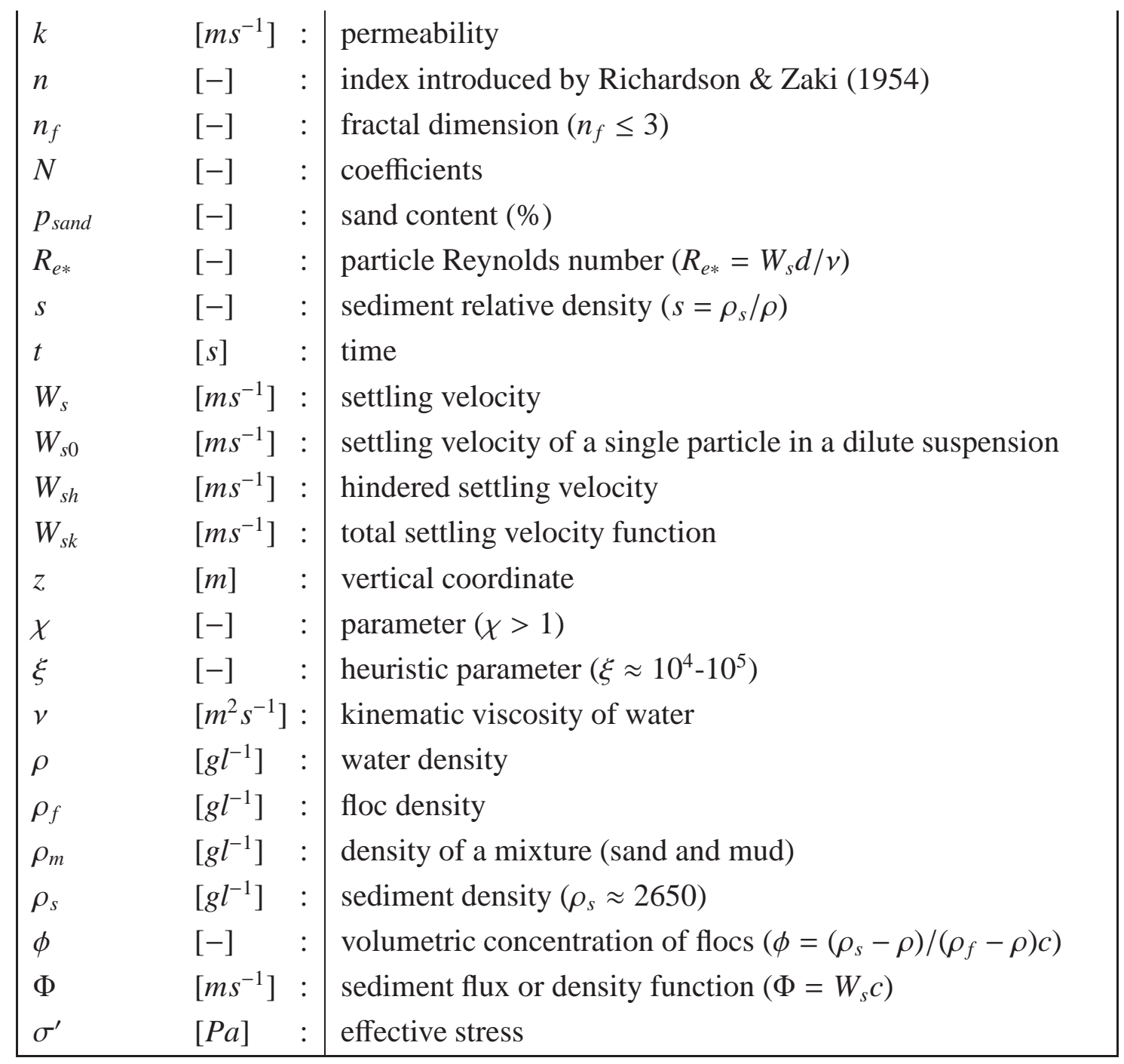

The following subscripts are used in this paper for the volumetric concentrations ( $c$ or $\phi):$

\begin{tabular}{|ll|l|}
\hline 0 & $:$ & initial value $(t=0) ;$ \\
${ }_{m}$ & $:$ & critical value for which the sediment flux is maximum; \\
mix & $:$ & value calculated for a mixture (water + sediments -sand, mud-); \\
${ }_{c r}$ & $:$ & $\begin{array}{l}\text { critical value above which only one interface will be observed during } \\
\text { a batch experiment; }\end{array}$
\end{tabular}


Author-produced version of the article published in Continental Shelf Research, vol. 31, p. 106-111. The original publication is available at http://www.sciencedirect.com/ - doi:10.1016/j.csr.2010.07.003

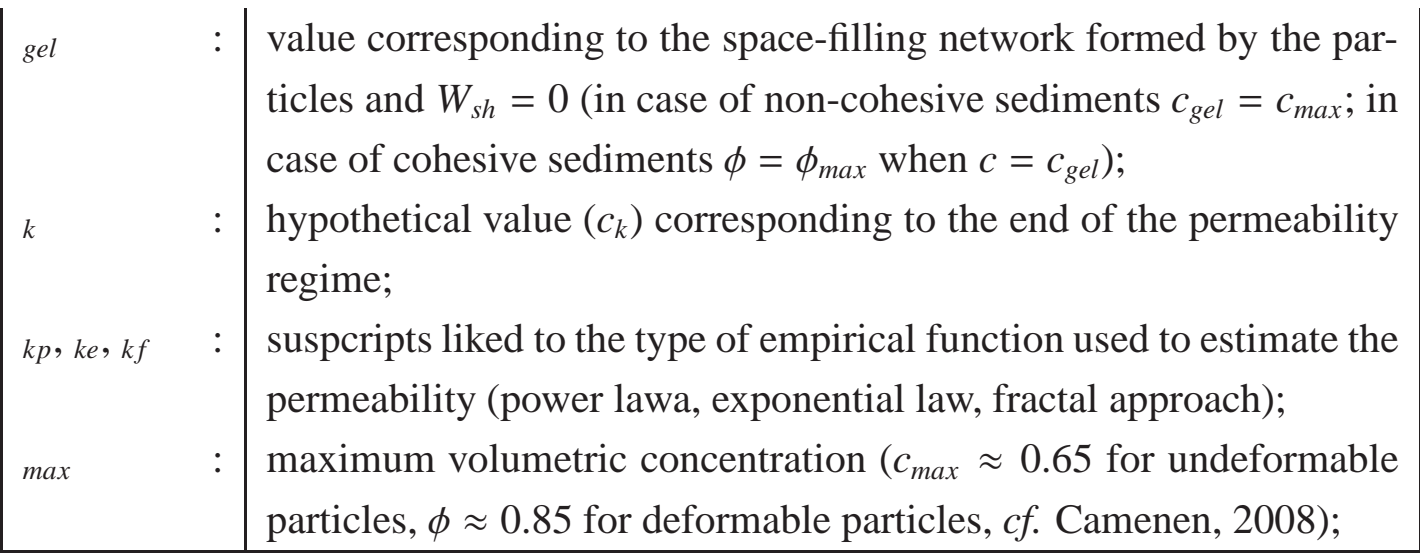

